\title{
Polyglycolic Acid Suture in Peripheral Nerve: An Electron Microscopic Study
}

\author{
ALAN R. HUDSON, JUAN M. BILBAO, and DANIEL HUNTER
}

SUMMARY: The aim of this experiment was to investigate the reaction of peripheral nerve tissue to a synthetic absorbable suture material. Polyglycolic acid suture material was placed within the sciatic nerve of rats and the $a b$ sorption of the material was investigated by means of electron photomicrographs. It was concluded that placement of polyglycolic acid into the peculiar environment of endoneurial tissues results in minimal scarring and in minimal disturbance of the surrounding nerve fibers. The material was progressively absorbed with minimal disturbance of intrafascicular structures.

RÉSUMÉ: Le but de cette expérience était d'investiguer la réaction du tissu du nerf périphérique au matériel de suture synthétique absorbable. La suture d'acide polyglycolique était placée dans le nerf sciatique des rats et l'absorption du matériel était investiguée par photomicrographies électroniques. Il a été conclu que le placement d'acide polyglycolique dans l'environnement particulier de tissus endoneuraux résulte en une cicatrice absolument minime et en une atteinte minime des fibres nerveuses environnantes. Le matériel était absorbé progressivement avec une faible modifcation des structures intrafasciculaires.

From the Department of Neurosurgery, St. Michael's Hospital, University of Toronto.

Reprint requests to Dr. Alan R. Hudson, Assistant Professor, Department of Neurosurgery, St. Michael's Hospital, Victoria and Queen, Toronto, Ontario, Canada.
Polyglycolic acid (PGA) suture has been subjected to laboratory investigations (Dardik et al, 1970, 1971; Hermann, 1970, 1973; Katz et al, 1970). It has also been tested clinically (Allmann, 1973; Anscombe et al, 1970; Cocke, 1972; Dardik et al, 1971; Echeverria et al, 1970; Lilly et al, 1973; Long et al, 1972; McCarthy, 1970; Miln et al, 1972; Rahman et al, 1972; Tompkins et al, 1972; Turner et al, 1972 and Wallace et al, 1970). This synthetic, non collagenous suture has a higher tensile strength than catgut and it is absorbed in tissues with minimal inflamatory reaction. To our knowledge no report exists as to its use in peripheral nerve surgery. This experiment was designed to examine the reaction of peripheral nerve tissue to placement of the suture, and to study its re-absorption in that peculiar environment which is maintained by the integrity of the endoneurial capillaries and perineurium.

\section{METHOD}

The sciatic nerves of 15 Wistar rats (200 gram) were transfixed with commercially available $6 / 0$ multifilament PGA suture, on a swedged needle. The procedure was conducted under clean, but not aseptic conditions. The suture filaments ran parallel to the intrafascicular fibers. A silk suture was placed in a neighboring muscle to mark the site. The animals ran about their cages in a normal manner and no example of foot pad ulceration or foot drop was observed. The animals were maintained under standard laboratory conditions, and remained in good general health. At intervals of $14 / 120$ days the animals were reanaesthetized and the nerves were re-exposed and fixed by the method of Morris et al (1972). The operator was guided to the biopsy site by the black silk suture as there was usually minimal tissue reaction at the point of PGA insertion. Entire transverse sections of the fascicle were embedded in plastic. Thick sections were examined by light microscopy and thin sections were studied on a Philips 300 electron microscope.

\section{RESULTS}

Examination of the suture in nerves of animals killed between fourteen and thirty days revealed twelve circular filaments of identical caliber which appeared weakly refractile under polarized light. These filaments were initially cut into ultra-thin sections with extreme difficulty because of the physical characteristics of the polymer. Each filament was of uniform electron density and there was no variation in sutures taken from different suture packs (Fig. 1).

Endoneurial macrophages are rarely seen in normal mammalian nerve, but they appeared rapidly in response to suture placement. The entire suture zone was initially surrounded by macrophages with abundant finger processes (Fig. 2). This surface configuration is associated with intense cellular activity and mobility. At the thirty and fifty day stage, these cells become more tightly packed between the individual suture filaments, so that the extra-cellular spaces diminished considerably (Fig. 3). The cell surfaces applied to the suture filament were smooth, but the free surface of those cells still exhibited some finger process formation. With the passage of time the entire suture zone be- 


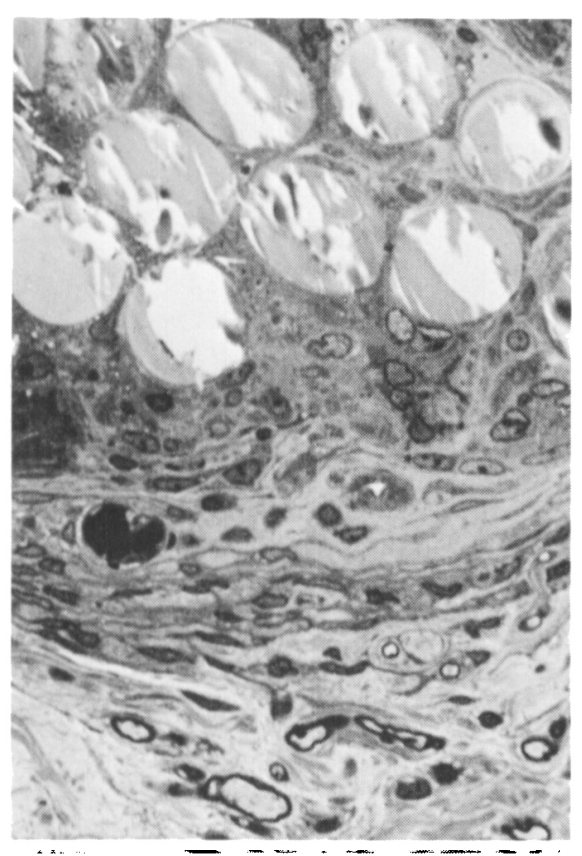

Figure 1. Cross section of multifilamentous P.G.A. suture. (Top) Individual filaments fragmented by microtome. Fibroblasts separate suture zone from nerve fibers. (Below) 400X.

came walled off from surrounding normal intrafascicular fibers. This wall consisted of two or three cell layers of macrophages and endoneurial fibroblasts (Fig. 1). There

Figure 2. 20 days. Multinucleated macrophages demonstrating surface finger processes. $4,254 \mathrm{X}$.

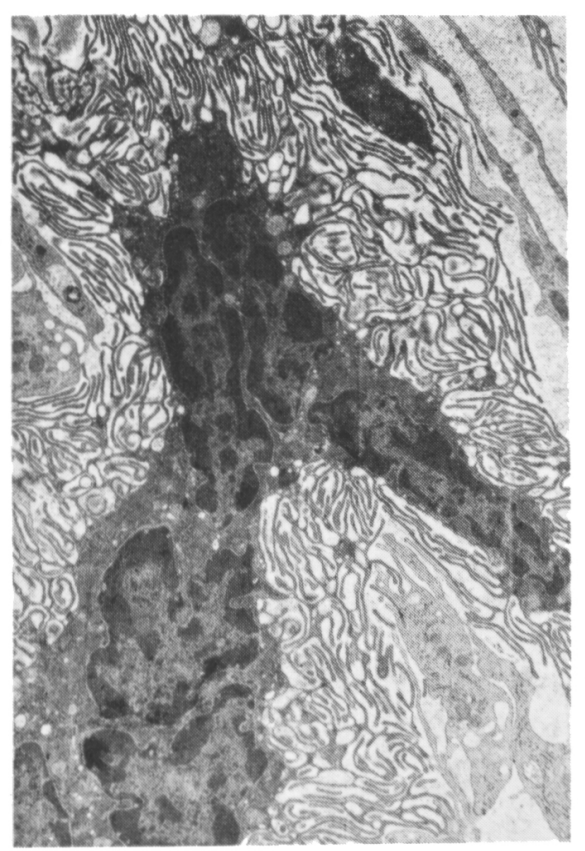

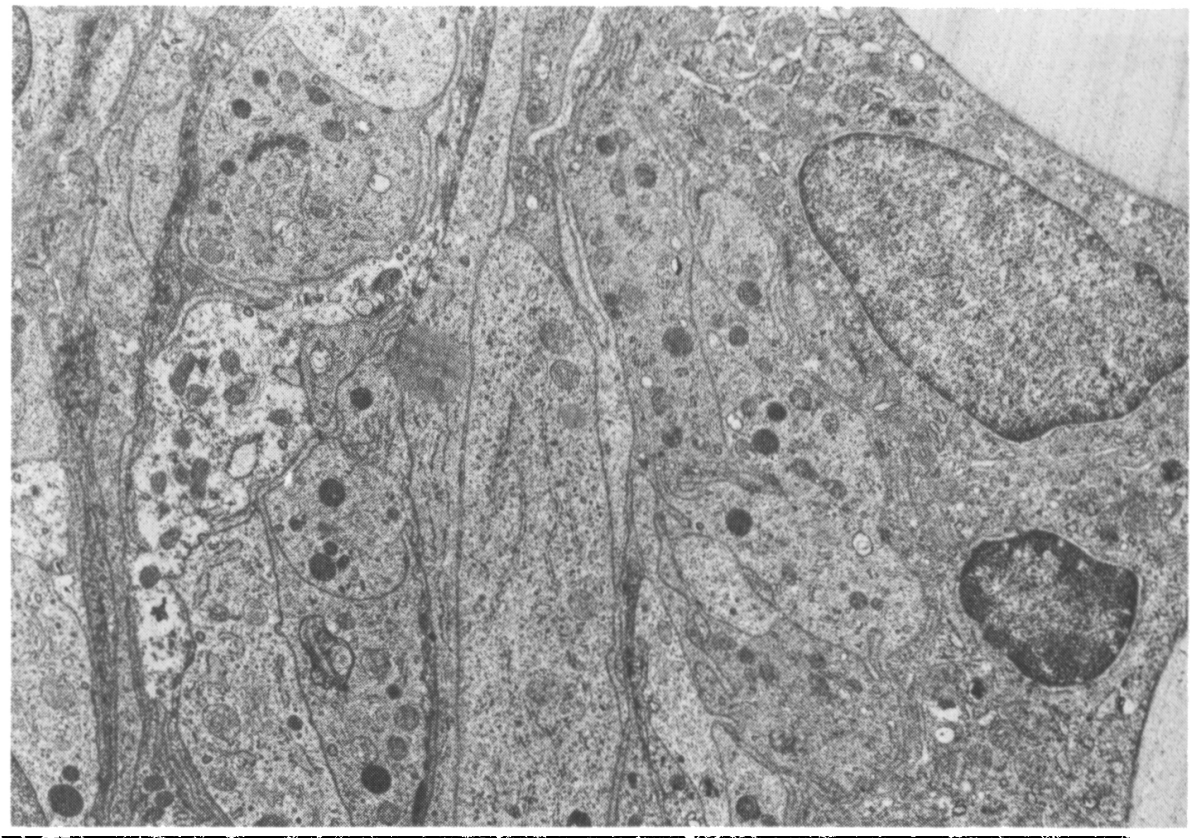

Figure 3. 35 days. Macrophages closely packed between partial profiles of two of the 12 P.G.A. filaments. (Right upper and lower corners) 5,550X.

were no abnormalities in the ultrastructure of myelinated and nonmyelinated fibers immediately adjacent to this partition. An occasional growth cone was observed, im- mediately adjacent to the suture zone.

At the fifty to seventy day stage the suture filaments exhibited changes in their physical structure.
Figure 4. 59 days. Partial profile of a single P.G.A. filament. (Upper right) Membrane bound inclusions in surrounding cell - probably P.G.A. polymer. 17,991X.

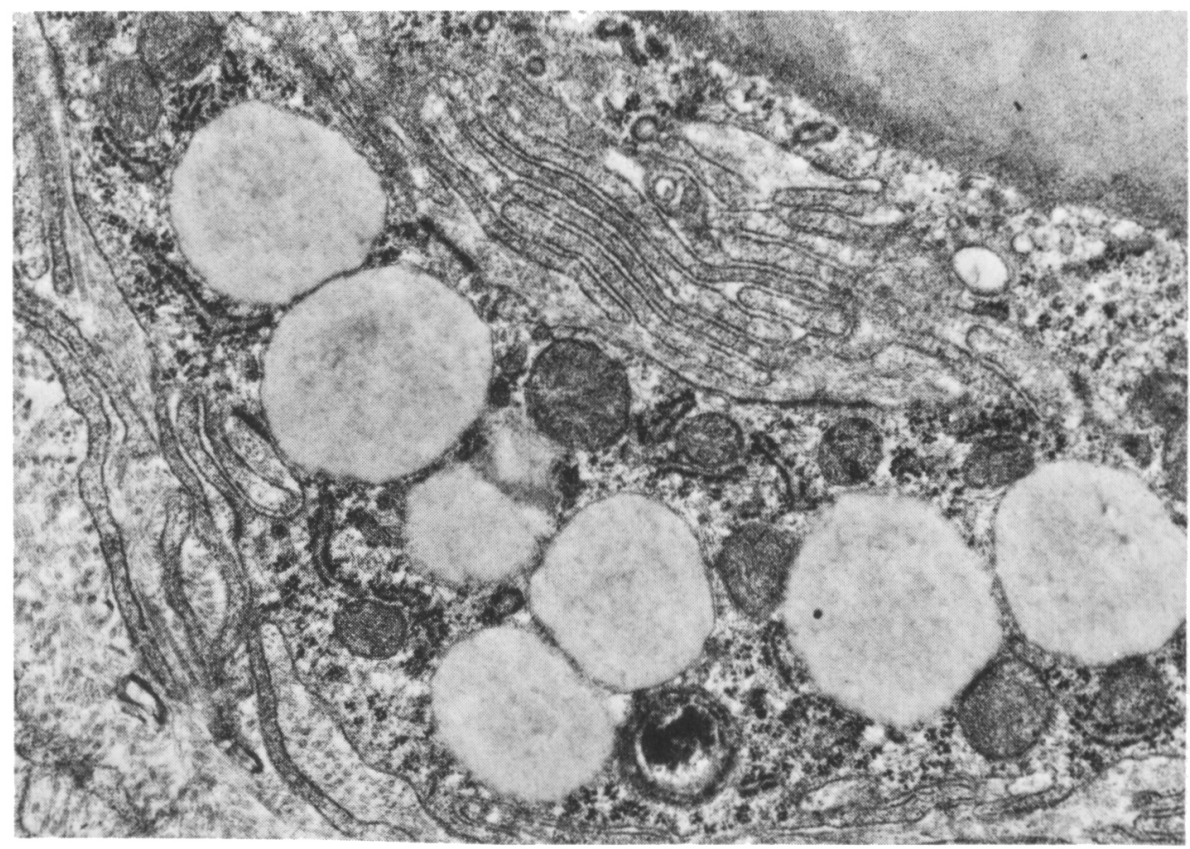




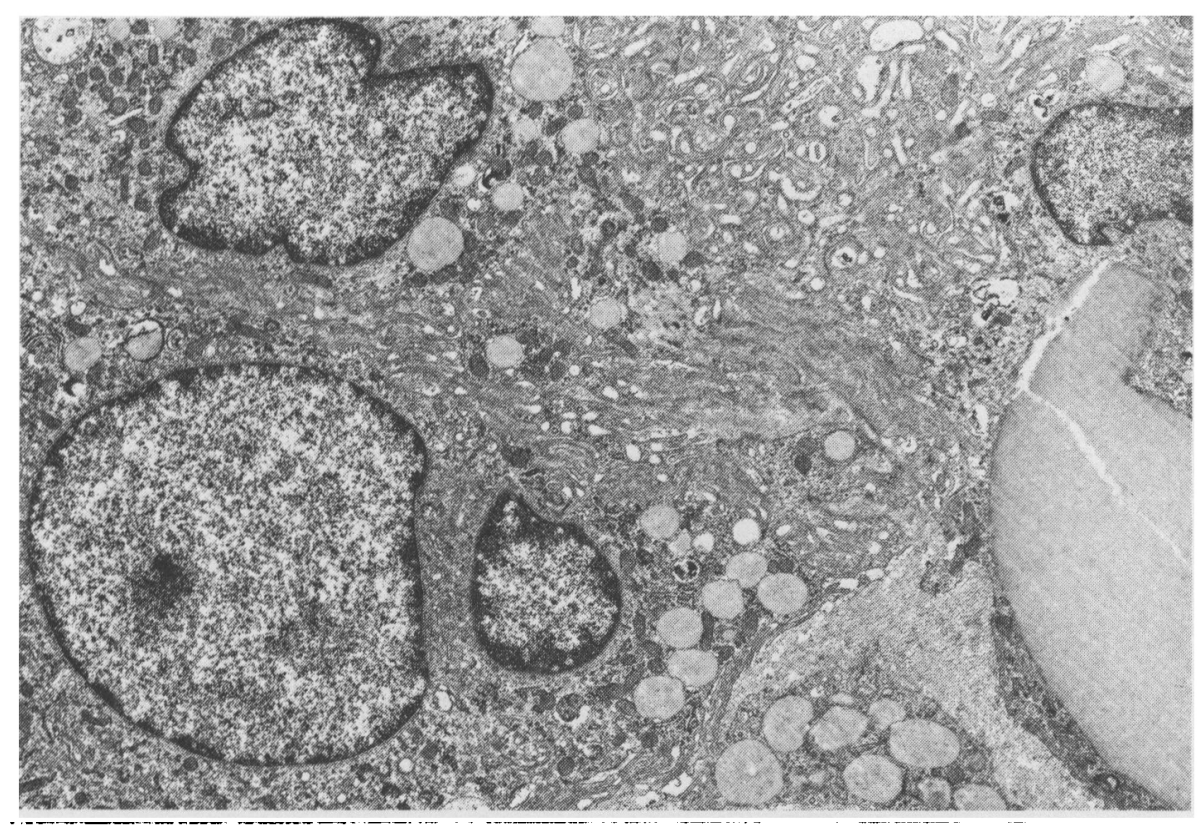

Figure 5. 80 days. Irregularity in the outline of suture filaments. (Right) Numerous intracytoplasmic vacuoles with the same electron density as P.G.A. polymer. $4,362 X$.

Their refractability when viewed with a polarizing microscope disappeared and this was associated with greater ease in sectioning the individual filaments with the ultramicrotome. At no stage did the individual filaments swell. Collagen

fibers were now abundant and separated reactive cells in the interfilamentous zone. The cytoplasm of the macrophages now contained abundant rough endoplasmic reticulum, aggregations of mitochondria and lysosomes. The

Figure 6. 110 days. Single cell contains 4 polymer fragments, of varying electron density and size. 10,367X.

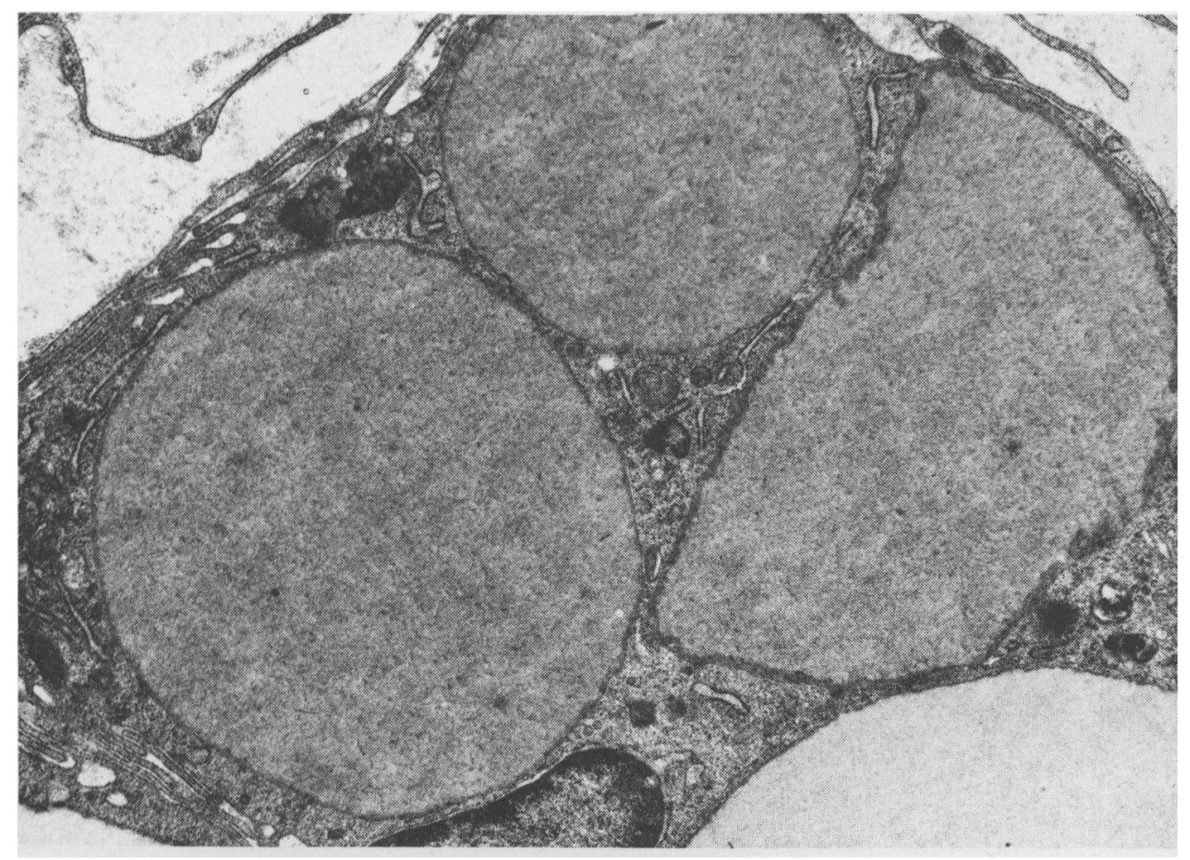

increase in organelle density was striking when compared to the cellular ultrastructure of specimens examined earlier in the series. Membrane bound vacuoles, with the same electron density as the PGA filaments, were seen in the cytoplasm of these very active cells (Fig. 4).

Evaluation of the eighty day biopsy revealed that the suture filaments were no longer circular in profile. Fewer than 12 suture filaments weie present. All sections were transverse but it is possible that the longitudinal continuity of the filaments was broken at this stage. The PGA filaments appeared eroded, and inclusions, having the same electron density as the suture material itself, were again seen within the cytoplasm of the tightly applied, surrounding macrophages (Fig. 5.)

The sciatic nerve of the animals sacrificed after one hundred days still contained fragments of polyglycolic acid material. Multinucleated large cells were seen containing three or four profiles of thinned out suture filaments (Fig. 6). With progressive shrinkage of the

Figure 7. 110 days. Marked reduction in size of suture zone. (Top) It occupies less than one-fifth the area, compared with figure 1. 400x.

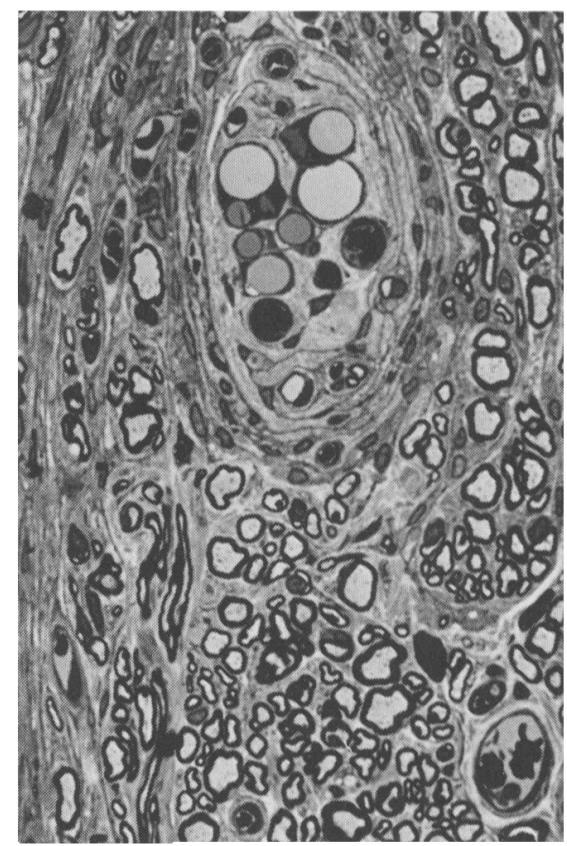




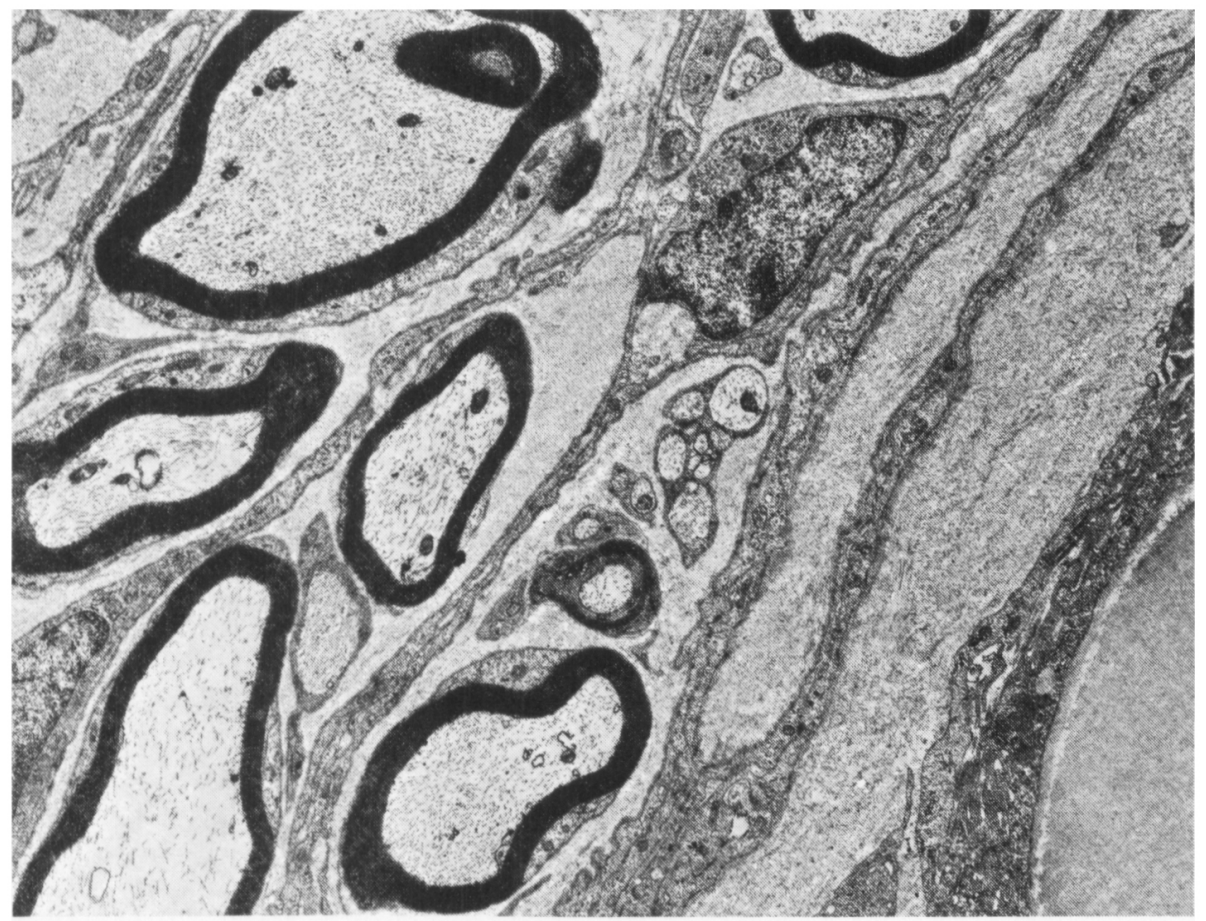

Figure 8. 80 days. Normal myelinated and non-myelinated fibers (left) in close proximity to a P.G.A. filament (right) which shows surface erosion. $4,362 \mathrm{X}$.

individual suture filaments, the overall suture zone was markedly reduced in cross sectional area (Fig. 7). The suture material, however, was still clearly identifiable by both light and electron microscopy. At the periphery of the suture zone, the PGA fragments remained separated from the normal myelinated and non-myelinated nerve fibers by $2-3$ layers of cell processes (probably of macrophagic origin) collagen fibers, and elongated cell processes exhibiting a basement membrane. This latter structure is indicative of Schwann cell origin. We had anticipated that the 120 day animal would not show any evidence of PGA material. Absorption in this environment, however, was prolonged and this was just as well because the area of the suture zone had so diminished that it would have been extremely difficult to find had all the suture been absorbed.

Capillaries were rapidly formed following suture placement, and were present in the suture zone, between the suture filaments. These endoneurial capillaries had a normal histological appearance. No wound infection occurred and bacteria were never seen within the multifilament- ous suture. Polymorphonuclear cells were never seen. Neither plasma cells, mast cells, or lymphocytes were identified.

\section{DISCUSSION}

The uniformity of the suture filaments is presumably related to the manufacturing process. The histology of each nerve remained in the expected progression, suggesting uniformity of suture absorption. No animal appeared to be out of sequence. The initial cellular response to the PGA suture insertion is that of reaction to the injury of any suture placement. This was followed by a period of relative quiescence during which time the entire suture zone was walled off from the surrounding fascicle and the individual suture filaments were closely surrounded by macrophages. This was followed by a period of suture filament absorption and concomitant overall suture zone shrinkage.

Throughout the period of the experiment the most outstanding feature was the lack of damage to the neighboring nerve fibers (Fig. 8). There was no progression of the partial nerve injury resulting from suture placement, presumably be- cause the sites of the blood nerve barrier, the perineurium and capillary, were undisturbed (Kline, 1972). It would thus appear that the process of PGA absorption is an extremely local affair and does not interfere with the histology of the fibers within that fascicle. The suture filaments were eroded at their periphery and fragments were seen within the surrounding macrophages, where it is presumed that hydrolysis to $\mathrm{CO}_{2}$ and $\mathrm{H}_{2} \mathrm{O}$ occurs.

Clinical suture placement is made preferrably through the epineurium or perineurium. The suture material was examined as it passed through these nerve layers and the sequence of histological change paralleled that previously described in other tissues. The presence of these suture filaments in the perineurial tissues had no effect on the underlying intrafascicular structure. In this experiment the suture material was specifically placed within the fascicle as we wished to observe the effect of the suture placement and absorption on the functioning nerve elements, lying in a mileu maintained by the perineurium and endoneurial capillaries, as this had never been previously described.

It has already been established that PGA suture is strong and easy to handle. The purpose of surgical suture in the divided peripheral nerve is to maintain fascicles in opposition until the regenerating units of axon clusters have passed from the proximal fascicles into the endoneurial environment of the distal fascicles, and, until the point is reached at which the physical continuity of the nerve is strong enough to no longer require artificial support. Beyond that point sutures serve no purpose and may possibly have a deleterious effect. The use of collagenous, naturally occurring, sutures in peripheral nerve has been abandoned as the reaction to their placement was excessive and the resulting scar tissue blocked axonal transmission. This synthetic polymer, with its predictable and progressive absorption, causes minimal reaction and completely disappears. Now that the extremely low reactivity in nerve has been estab- 
lished, it would be appropriate to examine the use of this suture in higher experimental animals and, at the same time, to check its holding power in the suturing of divided nerves.

\section{ACKNOWLEDGEMENTS}

Equipment supplied by MRC Grant No. MA3993, 60 P.G.A. suture (Dexon) supplied by Davis \& Geck.

\section{REFERENCES}

ALLMAN, F. L. (1973). Surgery, Gynecology \& Obstetrics, 136, 607-610.

ANSCOMBE, A. R., HIRA, N., and HUNT, B. (1970). The use of a new absorbable suture material (polyglycolic acid) in general surgery. British Journal of Surgery, 57, 917-920.

COCKE, W. M. (1972). Dexon - a new suture material; its use in plastic surgery. Southern Medical Journal, 65, No. 5, 629-630.

DARDIK, H., DARDIK, 1., KATZ, A. R., SMITH, R. B., SCHWIBNER, B. H., and LAUFMAN, H. (1970). A new absorbable synthetic suture in growing and adult primary vascular anastomoses: Morphologic study. Surgery, 68, No. 6, 1112-1121.

DARDIK, H., DARDIK, I., and LAUFMAN, H. (1971). Clinical use of polyg. lycolic acid polymer as a new absorbable synthetic suture. American Journal of Surgery, 121, 656-660.

ECHEVERRIA, E., JIMENEZ, J. (1970). Evaluation of an absorbable synthetic suture material. Surgery, Gynecology \& Obstetrics, 131, 1-14.

HERRMANN, J. B. (1973). Changes in tensile strength and knot security of surgical sutures in vivo. Archives of Surgery, 106, 707-710.

HERRMANN, J. B., KELLY, R, J, and HIGGINS, G. A. (1970). Polyglycolic acid sutures. Archives of Surgery, 100, 486-490.

KATZ, A. R., TURNER, R. J. (1970), Evaluation of tensile and absorption properties of polyglycolic acid sutures. Surgery, Gynecology \& Obstetrics, 131, 701-716.

KLINE, D. G. (1972). The neuroma in continuity. Surgical Clinics of North America, 52, No. 5.

LILLY, G. E., OSBON, D. B., HUTCHINSON, R. A., and HEFLICH, R. H. (1973). Clinical and bacteriologic aspects of polyglycolic acid sutures. Journal of Oral Surgery, 31, 103-105.

LONG, W. W., DERRICK, F. C. (1972). Use of polyglycolic acid suture in circumcision. Southern Medical Journal, 65, No. 6.
McCARTHY, W. H. (1970). A new synthetic absorbable suture material: A clinical trial of polyglycolic acid suture in general surgery. Australian \& New Zealand Journal of Surgery, 39, No. 4, 422-424.

MILN, D. C., O'CONNOR, J., DARLING, R. (1972). The use of polyglycolic acid suture in gastrointestinal anastomosis. Scottish Medical Journal, 17, 108-110.

MORRIS, J., HUDSON, A. R., WEDDELL, G. (1972). A study of degeneration and regeneration in the divided rat sciatic nerve based on electron microscopy. Z. Zellforsch, 124, 76-102.

RAHMAN, M. S., and WAY, S. (1972). Polyglycolic acid surgical sutures in gynecological surgery. Journal of Obstetrics and Gynecology of the British Commonwealth, 79, 849-851.

TOMPKINS, M. G., LEA, R. H. (1972). The use of polyglycolic acid sutures in obstetrics and gynecology. Canadian Medical Association Journal, 106, 675-677.

TURNER, F. W., GRISWOLD, W. A., JANZEN, H., MILNER, J. F., RIVERS, L. F. (1972). Clinical trial of a new absorbable synthetic suture material: Polyglycolic acid. Canadian Journal of Surgery, 15 , 389-393.

WALLACE, W. R., MAXWELL, G. R., and CAVALARIS, C. J. (1970). Comparison of polyglycolic acid suture to black silk, chromic, and plain catgut in human oral tissues. Journal of Oral Surgery, 28, 739-746. 